\title{
Osteoartritis piógena en el recién nacido
}

\author{
Drs, J. Cohen, ' J. P. Beca, ' I. Largo'
}

\begin{abstract}
Acute pyogenic arthritis during the newborn period

To detemine the ethiolugy of infections of the bones and joints during the newborn period a total of 29 patient charts hospitalized at the premature unit of the Luis Calvo Mackenna Hospital from November 1974 and June 1979 were analized.

In 24 , 1 \% of all cases more than one joint was infected the hip was the joint mast frequently involved (16 of 46 joints?.

The etiology was demostrated in 28 of 29 cases. Sinovial fluid pus and or blood cultures showed growth of 5 aureus or Klebsiella in 60,7 and $21,4 \%$ respectively, other hacteria isolated were $P$. aeruginosa in 7, $1 \%$ Proteus, $E$ coli and group $\mathbf{B}$ hemolytic Streptococcus being isolated each in 3,6 㖘 of cases.
\end{abstract}

La osteoartritis piógena del recién nacido constituye una entidad clínica de enorme interés y una causa importante de enfermedad, secuela y muerte en este periodo de vida. 1.2 Suele, además, plantear serios problemas de manejo clínico, en lo cual va involucrado el pronóstico del enfermo y de la o las articulaciones afectadas.

Resulta difícil establecer la frecuencia de la osteoartritis piógena neonatal, ya que se le reporta excepcionalmente en la literatura. ${ }^{3,4}$ En un estudio reciente de etiologías de las infecciones bacterianas neonatales, 5 la osteoartritis constituyó, junto a la meningitis purulenta, la tercera causa de infección grave en recién nacidos. Autores extranjeros la citan generalmente como complicación de septicemia o de procedimientos de enfermeria como lis venopunciones.

El Centro de Prematuros del Hospital Luis Calvo Mackenna es un centro de referencia al cual llega un número importante de niños con problemas ortopédicos. Por esta razón se han concentrado casos de osteoartritis piógena neonatal. El propósito del presente trabajo es analizar nuestra ex-

ICentro de Prematuros Hospital Luis Calvo Mackenna. Departamento de Pediatría - Facultal de Medicina Oriente. Universidad de Chile. periencia durante los últimos cinco años y conocer entre otros aspectos la frecuencia con que se presentan las distintas especies bacterianas como agentes etiológicos de la osteoartritis piógena, y cuáles son las articulaciones más frecuentemente afectadas en nin̄os recién nacidos.

\section{MATERLAL Y METODO}

Se analizaron las observaciones clinicas de 29 recién nacidos con osteoartritis piógena hospitalizados en el Centro de Prematuros del Hospital Luis Calvo Mackenna entre noviembre de 1974 y junio de 1979.

El diagnóstico de osteoatritis piógena se fundamentó en la existencia de un cuadro clínico compatible, la demostración de pus articular por punción articular o artrotomia, y en el hallazgo del agente etiológico en aquellos casos en que éste se aisló.

El grupo estudiado incluyó 13 recién nacidos de término y 16 de pretérmino; 13 del sexo masculino y 16 del sexo femenino. La edad gestacional tluctuó entre 28 y 41 semanas de gestación (promedio: 36,3 semanas), y el peso de nacimiento, entre 1.190 y $4.150 \mathrm{~g}$. (promedio: $2.403 \mathrm{~g}$.).

En cada uno de ellos se analizaron los datos de su procedencia, los antecedentes de embarazo y 
parto, la edad del diagnóstico, el cuadro clínico, las articulaciones comprometidas, las características del hemograma, los signos radiológicos, los agentes etiológicos encontrados y el tratamiento.

\section{RESULTADOS}

La procedencia de los 29 recién nacidos con osteoartritis piógena fue muy variada, ya que fueron enviados de hospitales del SNS y de clínicas privadas tanto de Santiago como de provincias.

El embarazo tie normal en 13 casos $(44 \%)$, el resto presentó diversas patologías, entre las que destacan: 4 casos de preclampsia, 4 madres con antecedentes de aborto del primer trimestre, y 3 casos de prurito gravídico. 19 recién nacidos $65.5 \%$ ) nacieron por parto vaginal, 9 por cesárea (31\%) y en un caso se desconoce el antecedente. El líquido ammiótico fue claro en $18 \operatorname{casos}(62 \%)$, con meconio en $5, y$ hubo 4 casos con líquido amniótico de mal olor y ruptura prematura de membranas de más de $\mathbf{2 4}$ horas.

Entre los antecedentes que potencialmente podrían haber contribuido a desencadenar el cuadro destacan: múltiples punciones femorales bilaterales, en 1 caso (artritis de ambas caderas), cateterización umbilical repetida, en 2 casos, y múltiples venopunciones, en 2 casos.

El cuadro clinico se presentó en todos los casos después de los 7 días de edad. Las manifestaciones clínicas (Tabla $\mathrm{N}^{\circ}$ 1) fueron aumento de volumen articular, limitación funcional y algún grado de enrojecimiento en todos los casos. Hubo además grave compromiso del estado general en 11

\section{Tabla N. ${ }^{0} 1$}

Osteoartritis piogena en el recién macido 29 pacientes Hospital L. Calvo Mackenna Nov. 74 - Jun. 79

\section{MANIFESTACIONES CLINICAS}

Aumentode volumen
Enrojecimiento
Linitación funciorial
Mal estado general
Palidez terrosa
Apneas
Fiebre
Hipotermia
Hepatoesplenomegalia

nıños, palidez terrosa en 10 y crisis de apnea en 9 casos. Signos como fiebre, hipotermia y hepatoesplenomegalia aparecen con menos frecuencia.

En 22 nin̄os (75.9\%) se comprometió una sola articulación. Las articulaciones afectadas se distribuyen en la forma siguiente: cadera en 9 , hombro en 7 , rodilla en 5 y codo en 1 caso. Los otros 7 recién naciłłos $(24.1 \%)$ tuvieron más de una articulacion afectada, 4 niños con dos articulaciones y 3 reciên nacidos con más de 2 articulaciones comprometidas (Tabla N. ${ }^{\circ}$ 2). En los 29 niños de esta serie hubo un total de $\mathbf{4 6}$ articulaciones conprometidas, de las cuales 16 fueron caderas $(35 \%)$ y 13 rodillas $(28 \%$ ). Las demás articulaciones se afectaron con menor frecuencia.

\section{Tabla N." 2}
Osteoartritis piógena en el recién nacido 29 pacientes
Hospital L. Calvo Mackerria
Nav. 74 - Jun. 79

\begin{tabular}{|c|c|}
\hline ARTICULACIONES COMPROMETIDAS & N. ${ }^{0} \%$ \\
\hline $\begin{array}{l}\text { Momoarticular } \\
\text { Cadera } \\
\text { Hombro } \\
\text { Rodilla } \\
\text { Codo }\end{array}$ & $\begin{array}{rr}22 & 75.9 \\
9 & \\
7 & \\
5 & \\
1 & \end{array}$ \\
\hline $\begin{array}{l}\text { Poliarticular } \\
2 \text { articulaciones } \\
+ \text { de } 2 \text { articulaciones }\end{array}$ & $\begin{array}{ll}7 & 24.1 \\
4 & \\
3 & \end{array}$ \\
\hline
\end{tabular}

En 21 casos (72\%) se tomó radiografía articular previo a la artrotomia, en el resto $n$ se realizó, por haber sido intervenidos de urgencia. El lov\% de las radiografías demuestra atumento de volumen de partes blandas, osteolisis de la metáfisis proximal en 15 casos y aumento del espacio articular en 13 de las articulaciones afectadas.

Los hemogramas realizados en 28 niños fueron normales en 4 y estuvieron alterados en 24 casos $(85.7 \%)$. Las alteraciones más frecuentes fueron desviación a izcuierda, neutrofilia, neutropenia y trombocitepenja, las cuales se combinaron en lat mayoria de los casos.

El agente cansal de la osteonartritis piógena se pudo demostrar en 28 de los 29 casos. En 2.5 de ellos se aisló el germen del pus articular, en 3 casos sólo en hemocultivos y en 10 oportunidades se aisló el mismo genmen en pus articular y hemo- 
c'ultivos. Los gérmenes aislados fueron St. aureus en 17 niños (60.7\%), Klebsiella sp. en 6 pacientes (21.4\%), Pseudomona aeruginosa en 2 casos (7.1\%) y Proteus sp., E. coli y Streptococcus B hemolítico Grupo B en un caso cada uno. En la
Tabla N." 3 aparecen los gérmenes aislados en los 28 casos de osteoartritis piógena con etiologia demostrada y el sitio de donde se obtuvo la muestra para el cultivo respectivo.

Tabla N." 3

Osteoartritis piógena en el recién ruacido Hospital L. Calvo Mackenna

Nov, $74 \cdot$ Jurn. 79

\begin{tabular}{|c|c|c|c|c|}
\hline \multirow[b]{2}{*}{ GERMENES AISLADOS } & \multirow[b]{2}{*}{ N." } & \multirow[b]{2}{*}{$\%$} & \multicolumn{2}{|c|}{ SITIO DE MUESTRA } \\
\hline & & & PUS ARTICULAR & HEMOCULTIVO \\
\hline Staphylococeus aureus & 17 & 60.7 & 17 & 6 \\
\hline Klebsiella sp. & 6 & 21.4 & 5 & 3 \\
\hline Pseudomonas aeruginosa & 2 & 7.1 & 2 & 1 \\
\hline Proteus sp. & $\mathbf{1}$ & 3.6 & 1 & 1 \\
\hline E. Coli & 1 & 3.6 & - & 1 \\
\hline Strep. B hemol. grupo B & 1 & 3.6 & - & 1 \\
\hline lotal & 28 & 100.0 & 25 & 13 \\
\hline
\end{tabular}

El tratamiento de los niños con osteoatritis piógena fue médico-quirúrgico. El tratamiento médico incluyó, además de las medidas generales y del tratamiento de los cuadres iniciales o intercurrentes, la antibioterapia prolongada (por lo menos 21 días). Todos los casos en que se demostró Staphylococcus aureus se tratarun con una penicilina resistente a $B$. lactamasa (Cloxacilina o Flucloxacilina), como droga única en 14 casos, y asociada a un aminoglicósido (Annikacina o Gentamicinil) en 3 niños. En los casos en que se demostró cono agente etiologico una enterobactereacia, el tratamiento fue un aminoglicósido como droga ínica en 5 casos (Amikacina), y asociado a una penicilina semisintética en 3 , pero en 2 recién nacidos en quienes se aisló Klebsiella sp. sc uso Cefradine y Rifampicina como drogra única, segum antibiograma. En los 2 casos en que se encontró Pseudomona aeruginosa se les administró Anikacina, asociado a Ampicilina en un caso, y a Carbencilina en el otro. El caso en que el agente etiológico fue Streptococcus hemolítico Grupo B, se administró Penicilina asociada a Cloxacilina. En el caso en el cual no hie posible aislar agente etiológico se uso Cloxacilina asuciacta a Amikaci$n_{i a .}$ El tratamiento quirúrgico se realizó mediante artrotomia evacuadora, drenaje, instalaciones de antibióticos intraarticulares (en los anos $74-75$ ) e inmovilización prolongada.

\section{DISCUSION}

La osteoartritis piogena neonatal constituye un cuadro relativamente frecuente en el Centro de Prematuros del Hospital Luis Calvo Mackenna, lo cual no es extrapolable a la realidad nacional por ser éste un centro de referencia que concentra esta patología.

Además de los factores etiopatogénicos que dependen del agente, el ambiente y el huésped juegan un rol fundamental." Es así como entre los intecedentes de los recién nacidos que presentaron osteoartritis piogena llama la atención que un gran número de ellos corresponde a recién nacidos de preténnino y niños de bajo peso, los culales por sus caracteristicas inmunológicas tienen mayor riesgo de sufrir infecciones graves.

Tradicionalmente se ha tratado de explicar la mayor susceptibilidad a infecciones del recién nacido, porque en ellos se encuentran niveles bajos de inmunoglobulina M. pasiva. Sin embargo, no es esto lo más importante, puesto que existen otros factores que son primordiales en la inmunidad a infecciones bacterianas que tambièn están deficitarias en esta época de la vida, como la falta de factores séricos termoláhiles relacionados con el sistema del complemento, que traduce un déficit en la opsonización y por ende en la fagocitosis. ${ }^{9}$ La migración y capacidad fagocítica de los poli- 
mortonucleares están deprimidos especialmente en los niños de pretémino, y probablemente sea éste el factor más importante en la defensa de un huésped contra los agentes bacterianos. ${ }^{10}$

El sexo y los antecedentes prenatales no hivieron relación importante que destacar en este estudio.

En cuanto al análisis de los factores del ambiente, destacan punciones femorales, cateterizaciones umbilicales, venopunciones múltiples, etc., en aquellos recién nacidos en que estus antecedentes pudieron haber actuado como desencadenantes.

Las manifestaciones clínicas que hicieron sospechar el diagnóstico y que estuvieron presentes en el $100 \%$ de los casos, no siempre fueron síntomas categóricos; con frecuencia éstos fueron advertidos inicialmente por personal de enfermería, por ello insistimos en que son signos que por lo general no están presentes y que hay que buscar en forma dirigida.

El hemograma en estat serie constituyǵ un recurso de diagnóstico útil de infección grave, ${ }^{1.9}$ ya que más del $85 \%$ de los casos presentó alteraciones de importancia en el recuento de neutrófilos, recuento de baciliformes $y$ recuento de plarjuetas al frotis.

En la etiología bacteriana de la osteoartritis piógena predominan Staphylococcus aureus y Klebsiella sp., lo que estí en concordancia con publicaciones anteriores. 5 Por ello la elección de un antibiótico frente a casos con agente etiológico desconocido debe ser asociada a incluir una droga antiestafilocícica más un aminoglicósido, de acuerdo con estudios locales periódicos de sensibilidad.

Con respecto a la infección estafilociocicia, hay que destacar que en el recién nacido existen niveles séricos bajos del factor reactivador de la coagulasa (F.R.C.), proteína de alto peso molecular que interacciona con la coagulasa que produce el Staphylococcus aureus, permitiendo delimitar los procesos supurativos. " Este déficit explicaría la tendencia observada en esta edad a presentar infecciones diseminadas.

En los 29 recién nacidos con osteoartritis piógena hubo un total de 46 articulaciones afectadas, debido a que en 7 nin̄os se presentó conpromiso poliarticular, sin tener relación este fenómeno con el agente causal. Hay que destacar que del total de las articulaciones afectadas, la cadera liue la más frecuente.
La cadera es la articulación más frecuentemente comprometida, debido probablemente al tipo de circulación arterial terminal tan peculiar que tiene la cabeza lemoral. ${ }^{12}$

Faltan datos de seguimiento; pero éste se realizó por más de un año en 8 niños, 7 de los cuales mostraban grave compromiso de la función articular y diversas alteraciones radiológicas correspondientes todos ellos a secuelas de osteoartritis de caderas.

Un mejor pronóstico dependerá de un diagnóstico precoz; diagnóstico etiológico y antibioterapia especifica; drenaje del pus y tratamiento ortopédico adecuado.

Là prevención de la osteourtritis piógena neonatal depende en gran parte del adecuado manejo de aquellos factores obstétricos que disminuyan la prematuridad; y en las estrictas medidas de asepsia para el cuidado del recién nacido.

De esta revisión se puede concluir que la osteoartritis piogena neonatal es más frecuente en recién nacidos de pretérnino que de témino, que compromete con mayor probabilidad la cadera, $y$ que la etiología más fiecuentemente observada es St. aureus o Klebsiella en nuestro medio. Aunque no se tienen datos de seguimiento, el pronóstico articular es reservado y dependerá en gran parte de la precocidad del diagnóstico y de la especificidad del tratamiento.

\section{RESLMEN}

Con el objeto de conocer la etiología de la osteoartritis piógena neonatal y las articulaciones afectadas en muestro medio, se analizaron 29 observaciones clínicas de recién nacidos con ese diagnóstico hospitalizados en el Centro de Prematuros del Hospital Luis Calvo Mackenna entre novienbre de 1974 y junio de 1979.

En todos los casos se encontró compromiso articular focal acompañado de algin grado de compromiso del estado general. Los signos tocales más frecuentemente encontrados fueron aumento de volumen, limitación funcional $y$ algín grado de enrojecimiento. En el $24.1 \%$ de los casos hubo más de una articulación afectada. La articulación más frecuentemente comprometida fue la cadera ( 16 de las 46 articulaciones comprometidas?. Los signos radiológicos encontrados fueron: aumento de volumen de partes blandas como signo principal, aumento del espacio articular y osteolisis de la metáfisis proximal. 
El agente causal se pudo demostrar en 28 de los 29 casos. Los cultivos de pus articular y/o hemocultivos demostraron desarrollo de St. aureus en el 60,7\% y Klebsiella Sp. en 21,4\% de los casos. Los demás gémenes encontrados fueron Pseudomonas aeruginosa en un 7.1\%; Proteus, E. Coli y Streptococcus B hemolítico Grupo B en un $3.6 \%$ cada uno.

Se concluye que la osteoartritis piógena neonatal es una afección grave, que afecta con mayor frecuencia la cadera, de etiología preferentemente estafilocócica y que debe ser tratada como urgencia médico-quirúrgica.

\section{REFERENCIAS}

${ }^{1}$ Samilson, L. Robert; Bersani, A. Fraule, and Watkins, B. Melcis. Acute Suppurative Arthritis in infants and children. Pediatricis, Vol. 21 : 803, May 1958.

2 Neison, D. Juhn; Koontz, C. Wuyne. Septic Arthritis in inliunts and children: Review of 117 cases. Pediatrics, Vol. 38, N." 6, Part. I, p. 966-971; Dec. 1966.
${ }^{3}$ Rizizardisi, M. Beca J. P. et al. "Manual de Perinatolugia", Cap. XVI. Colección Medicina Chilena, 1979.

4 Witson H., Ekhenuald M. Sepsis neonatorum. Pediatr. Clin North America 21: 571, 1974.

5 Hershovic, P.; Toso, A.; Beca,j. P.; Donoso, É. Etiología de las infecciones bacterianas neonatales. Rev. Chil. Ped. 50: 42; 1979.

6 Howard, J. Philip, Sepsis in inmmal and Premature infants with Ickalization in the hip joint Pediatrics, Vol. 18; 279 , 1957.

7 Astes, S. Fussuet and Arender M. Gregory. Septic Arthritis of the hip: A complication of femoral Venipunture. Pediatrics, Vol. 38: 837, 1966).

${ }^{B}$ Zetatia, $M$. Mario. Infecciones bacterianas en el recién nacido. Pediatría 19: 253, 1976.

9 Miller, Michael. Phagocyte Function in Neonate. Selected aspects. Pediatrics Supp. Vol. 64 (5): 709, 1979.

10 Suydernam Ralph and Pike Marilyn. Disonders of Leucocyte Chemotaxis. Pediat. Clin. North Americ. 24: 2, 377 May 1977.

LI Humnelkuwtp, C. It. Jr. and Lebovitz, J. L. The role of coagulase in Staphylocoxcol infections, Intem. Med 45: 748, 1956.

12 Tessut, L., Latarget A. Anatomía Humana, Capitulo III, Artículo V, p. 364, Tomo Il. Salvat Editores S.A., 1968.

1.5 Zelatia, Mario; Garrite Violeto y Gionzalez Tina. "El recuento de Baciliformes en el diagnóstico de las infecciones bacterianas neunatales", Rey. Chile, Ped. 49: 7, 1978.

14 Oski y. Yistiman. Problemas hematológicus en el recién nacido. Vul. IV, Cap. I. Problemas actuales de la pediatría clínica. Ed. cientifico médica, 1968. 